\title{
CORRECTIONS
}

\section{Post-mastectomy breast reconstruction}

In this Clinical Review (BMJ 2013;347:f5903, doi:10.1136/bmj. f5903), the legend for figure 2 and the table should have cited reference number 26 (not 24 , as was published).
Cite this as: BMJ 2013;347:f6810

๑ BMJ Publishing Group Ltd 2013 